\title{
Challenges and Opportunities of Grid Modernization and Electric Transportation
}

Robert L. Graham1, Julieta Francis², Richard J. Bogacz²

March 2017 


\section{Acknowledgments}

The authors appreciate the sponsorship of the U.S. Department of Energy's (DOE) Office of Energy Efficiency and Renewable Energy Vehicle Technologies Office who made this work possible. Extensive stakeholder inputs and peer reviews were considered in the drafting of this report. The external reviewers selected were all recognized experts in the electric power or transportation sector. Their advice was considered on that basis, not as representatives of any particular organization or institution. Their comments were incorporated as appropriate, which greatly improved the accuracy and quality of the report. Any remaining inconsistencies or errors are not to be attributed to the reviewers. The individuals that participated in the review process are listed below. Their organizational affiliation is listed only to assist in identification and does not imply any form of endorsement. Special thanks go to Kelly Barr and John DiStasio, whose vision and guidance helped shape this paper.

Gregory Adams

Salt River Project

Thomas Ashley

Greenlots

Kelly Barr

Salt River Project

Michael Berube

Department of Energy

Gil Bindewald

Department of Energy

Dan Bowermaster

Electric Power Research Insitute

Aleksandra Buleska

Fiat Chrysler Automobiles

Kerry Cheung

Department of Energy

Watson Collins

Eversource Energy
John DiStasio

Large Public Power Council

Ben Farrow

Puget Sound Energy

Keith Frost

Commonwealth Edison

Company

Rish Ghatikar

Greenlots

Mike Hoffman

Pacific Northwest National

Laboratory

Kathy Kinsey

Northeast States for

Coordinated Air Use

Management

Rao Konidena

Midcontinent Independent

System Operator

Kevin Lynn

Department of Energy

Stephanie Morse

Vermonet Energy Investment

Corportation
Richard Mueller

DTE Energy

Bill Parks

Department of Energy

Emmaline Pohnl

Drive Oregon

Jim Pratt

Salt River Project

Nancy Ryan

Energy \& Environmentla

Economics Inc.

Reuben Sarkar

Department of Energy

Kellen Schefter

Edison Electric Institute

Lee Slezak

Department of Energy

Sam Spofforth

Clean Cities Ohio 


\section{Purpose}

The purpose of this white paper is to provide electric company and public power company executives with information addressing the importance of the interaction between transportation electrification and the electric power grid. Grid investments that support electric vehicle transportation as a part of planned modernization efforts can enable a more efficient and cost-effective transition to electric transportation and allow investor-owned electric companies and public power companies to realize new revenue resources in times of flat or declining loads.

\section{Executive Summary}

Grid investments that support electric vehicle deployments as a part of planned modernization efforts can enable a more efficient and cost-effective transition to electric transportation and allow investor-owned electric companies and public power companies to realize new revenue resources in times of flat or declining loads. This paper discusses the challenges and opportunities associated with an increase in plug-in electric vehicle (PEV) adoption and how working together both sectors stand to benefit from closer integration.

It is critical to examine the importance and value of PEV integration with the electric power grid by recognizing the advances that electric vehicles have made and understanding opportunities resulting from integrating the modern grid with PEVs. After being in existence for more than 100 years, the electric power and transportation sectors are seeing significant changes at a rapid pace. The push for greener technologies and an increase in PEV availability have made electrification of the transportation sector conceivable. Because PEVs rely on the electric power grid, increased PEV adoption and the development of their charging infrastructure should closely align with grid modernization efforts.

The growth of PEVs is coming at the same time the electric power sector is experiencing significant changes in generation mix and load. These changes are driven by a variety of factors including new technologies, such as $350 \mathrm{~kW}$ DC Fast Charging and wireless charging, environmental policy, and consumer expectations. The new technologies are making it possible to operate the electric power grid more efficiently and effectively, but it requires capital investments and an increased need for data management and coordination at all levels and among a number of energy system participants. The technology and data revolution also creates a new intersection between transportation, buildings, and electric companies. PEVs present opportunities for growth and innovation as well as economic gains, improved environmental performance, and new choices for customers looking to reduce their total energy consumed.

The releationship between grid modernization and electric transportation is complementary, thus both sectors ought to address critical issues such as reliability, privacy, data management, affordability, and security jointly. As the future evolved, we can benefit from increasingly efficient movement of goods and people in a coordinated, reliable, and environmentally friendly manner.

To realize the full potential of the opportunity, however, several technical challenges require the attention of both sectors. With some thoughtful planning and analysis, electric transportation and grid modernization efforts can provide opportunities for growth and innovation in both industries. This discussion paper is not intended to provide policy recommendations but rather to initiate important dialogue that will benefit both sectors. 


\section{Introduction}

PEVs have the potential to revolutionize the U.S. transportation fueling system. Because they run on electricity they rely on the electric power grid for their fuel. To incorporate an entire sector's power needs into our electric grid is a considerable challenge. However, if carefully orchestrated, the integration can create many opportunities for both sectors. This white paper will examine the importance and value of PEV integration with the electric power grid by identifying challenges, then describing sector advances, and finally by detailing several opportunities resulting from integrating the grid with electric transportation.

\section{Challenges}

Automakers are working to introduce new PEV technologies, state and local policymakers around the country are encouraging the use of PEVs, and significant research has reduced the cost of PEV technologies. As market share grows, actively planning for vehicle grid integration is important. For vehicle-grid integration to be successful the challenges needed to be well articulated and defined. The foundational work in this area was the Multi-Lab EV Smart Grid Integration Requirements Study, ${ }^{1}$ initiated by DOE in which national laboratories identified several key factors that when implemented should bring increased benefit from PEV integration into the grid. The study includes the current state of the transportation and electric power sectors, analysis on the magnitude and variability of PEVs as a grid source, and recommended actions to support greater adoption of vehicle-grid integration. This paper builds on that report by working with electric power sector stakeholders. The stakeholders' input is indispensable to identify which challenges are on the critical path for vehicle-grid integration. Prioritizing the challenges across the entire sector was neither possible nor necessary for this discussion. The challenges identified by the group are thoroughly described in the bulleted list below.

- Cyber security: Cyber security is both a concern and challenge especially in light of well publicized vehicle hacking incidents over the last two years. ${ }^{2,3,4}$ It is enough of a concern that the FBI released a Public Service Announcement on vehicle vulnerabilities in March 2016. ${ }^{5}$ Similar concerns are arising in the electric power sector as electric companies are upgrading to smart grids. To address some of these concerns The National Institute of Standards and Technology has produced a set of cybersecurity guidelines, called NISTIR 7628, for smart grid programmers across the globe. ${ }^{6}$ However, while the grid connection point is governed by grid cyber security standards and norms, PEVs are not. Without well-defined cyber security standards for PEVs and their connection to smart charging systems, these vehicles could be a weak link

\footnotetext{
1 “Multi-Lab EV Smart Grid Integration Requirements Study,” National Renewable Energy Laboratory (NREL). NREL/TP-5400- 63963, May 2015. [Online]. [Accessed 27 August 2015]. Available: http://www.nrel.gov/docs/fy15osti/63963.pdf

2 Andy Greenberg, "Hackers remotely kill a Jeep on the highway - with me in it," Wired.com, 21 July 2015. [Online]. [Accessed 18 January 2017]. Available: https://www.wired.com/2015/07/hackers-remotely-kill-jeep-highway/

3 Kim Zetter, "Researchers hacked a Model S, but Tesla's already released a patch,” Wired.com, 06 August 2015. [Online]. [Accessed 18 January 2017]. Available: https://www.wired.com/2015/08/researchers-hacked-model-s-teslas-already/

4 Leo Kelion, "Nissan Leaf electric cars hack vulnerability disclosed," BBC News, 24 February 2016. [Online]. [Accessed 18 January 2017]. Available: http://www.bbc.com/news/technology-35642749

“Motor vehicles increasingly vulnerable to remote exploits," Federal Bureau of Investigation, Alert Number I-031716-PSA, 17 March 2016. [Online] [Accessed 18 January 2017]. Available: https://www.ic3.gov/media/2016/160317.aspx\#fn1

6 “Cybersecurity: Plugging smart grid weaknesses," phys.org, 05 June 2013. [Online]. [Accessed 18 January 2017]. Available: https://phys.org/news/2013-06-cybersecurity-smart-grid-weaknesses.html
} 
introducing additional cyber security risks to the overall electric system. To help address this challenge, DOE has funded research in this area with a project on Diagnostic Security Modules for Electric Vehicle to Building Integration. ${ }^{7}$

- Privacy: Privacy of individual data is an important factor to individuals, companies, and governments. This is of particular concern with PEVs because they are used for transportation. If an individual's data goes unprotected, consumers' mobility could be tracked without their knowledge or consent. The complexity of privacy necessitates careful recognition of the specific challenges such as connectivity, cyber security standards, and uniformity.

- Modernization levels: Grid modernization efforts vary by electric company across the country. Some electric companies are focused on the ongoing replacement of aging infrastructure, others are working to interconnect greener and more distributed energy sources, while others are utilizing improved diagnostics to give grid operators more visibility into the system and enhance grid reliability, flexibility, and resiliency. Analysis of these current activities may provide useful lessons learned on their implications for transportation electrification. For example, the charging infrastructure for autonomous plug-in cars may have different grid requirements than for PEVs. The potential need to upgrade distribution equipment particularly at the point of power delivery for vehicle charging is not clear. Critical analysis can support distribution upgrading to adequately meet future charging capabilities.

- Reliability levels: With the invention of tablets, Wi-Fi, and smart phones, consumers are more connected and dependent upon a highly reliable grid than ever before. Additionally, as PEVs become more advanced, receiving information about traffic, weather, and other externalities will be important to operate safely. Audi of America announced that their 2017 Q7 and A4 models include the ability to receive traffic light information from advanced traffic management systems. ${ }^{8}$ These communication links, potentially powered by the grid, may require an even higher level of reliability to ensure safety of the overall transportation system. The higher reliability can be from the grid or the device itself through backup power sources.

- Big Data Management: Integrating transportation with the electric power sector adds complexity to the challenges associated with managing and processing large volumes of data quickly. The volume of data expected and the amount of data storage required is significant. Electric companies that already manage grid and consumer data could handle these additional data streams and abide by cyber security and privacy regulations.

- Modeling: Unlike the stationary loads on the grid today, PEVs are mobile loads able to appear at any charging point, adding complexity to the modeling of the grid and load forecasting. The information and level of fidelity necessary at the bulk electric system level is still being decided. When the PEV load becomes a challenge to the transmission system operators and transmission owners is not clear. Additionally, model interchange standards for distribution showing electric vehicle supply equipment (EVSE) connectivity would benefit utility and transportation planners so the model can be easily integrated and exchanged between all parties. Having the electric power and transportation sectors collaborate on an infrastructure model tool that can be used by communities to plan and verify PEV and EVSE investments would improve load forecasting and capital investment planning.

7 "DOE Grid Modernization Laboratory Consortium (GMLC) - Awards" Energy.gov, [Online]. [Accessed 18 January 2017].

Available: https://www.energy.gov/under-secretary-science-and-energy/doe-grid-modernization-laboratory-consortium-gmlc-awards

8 “Audi introducing first vehicle-to-infrastructure (V2I) service: Traffic light information system," Green Car Congress [Online]. [Accessed 13 September 2016]. Available: http://www.greencarcongress.com/2016/08/20160815-audi.html 


\section{Advances}

After being in existence for more than 100 years, the electricity and transportation sectors are seeing significant changes at a rapid pace. PEVs have made significant advances in the last few years and are becoming more competitive with traditional internal combustion engine vehicles. The demand for low-emission, energy-efficient technologies and an increase in PEV availability have made electrification of the transportation sector conceivable. With 16 plug-in hybrid electric vehicle models and 15 battery electric vehicle models 9 to choose from, this type of alternative fuel vehicle is widely available and increasingly cost effective. In December 2016, cumulative sales of PEVs topped 560,000 in the United States (including plug-in hybrid electric vehicles and battery electric vehicles) $)^{10}$ and about 373,000 people ${ }^{11}$ have submitted pre-order deposits on a Tesla Model 3 that will be available in 2017. This push coupled with a decrease in PEV purchase prices are making PEVs more prevalent within the transportation sector, both with fleet owners and private consumers. Because PEVs rely on the electric grid for power, increased PEV adoption and the development of their charging infrastructure should be closely aligned.

California, through issuing vehicle emissions standards stricter than federal vehicle standards and requiring automakers to produce zero emission vehicles (ZEVs), has implemented policies to further accelerate the battery electric and plug-in hybrid electric vehicle markets. Nine additional states - Connecticut, Maine, Maryland, Massachusetts, New Jersey, New York, Oregon, Rhode Island, and Vermont—have contributed to this acceleration by adopting California's ZEV program. Given the number of vehicles already sold and the enthusiasm for future models, the demand for these cars is expected to increase. ${ }^{12}$ Electric companies from California and Oregon,

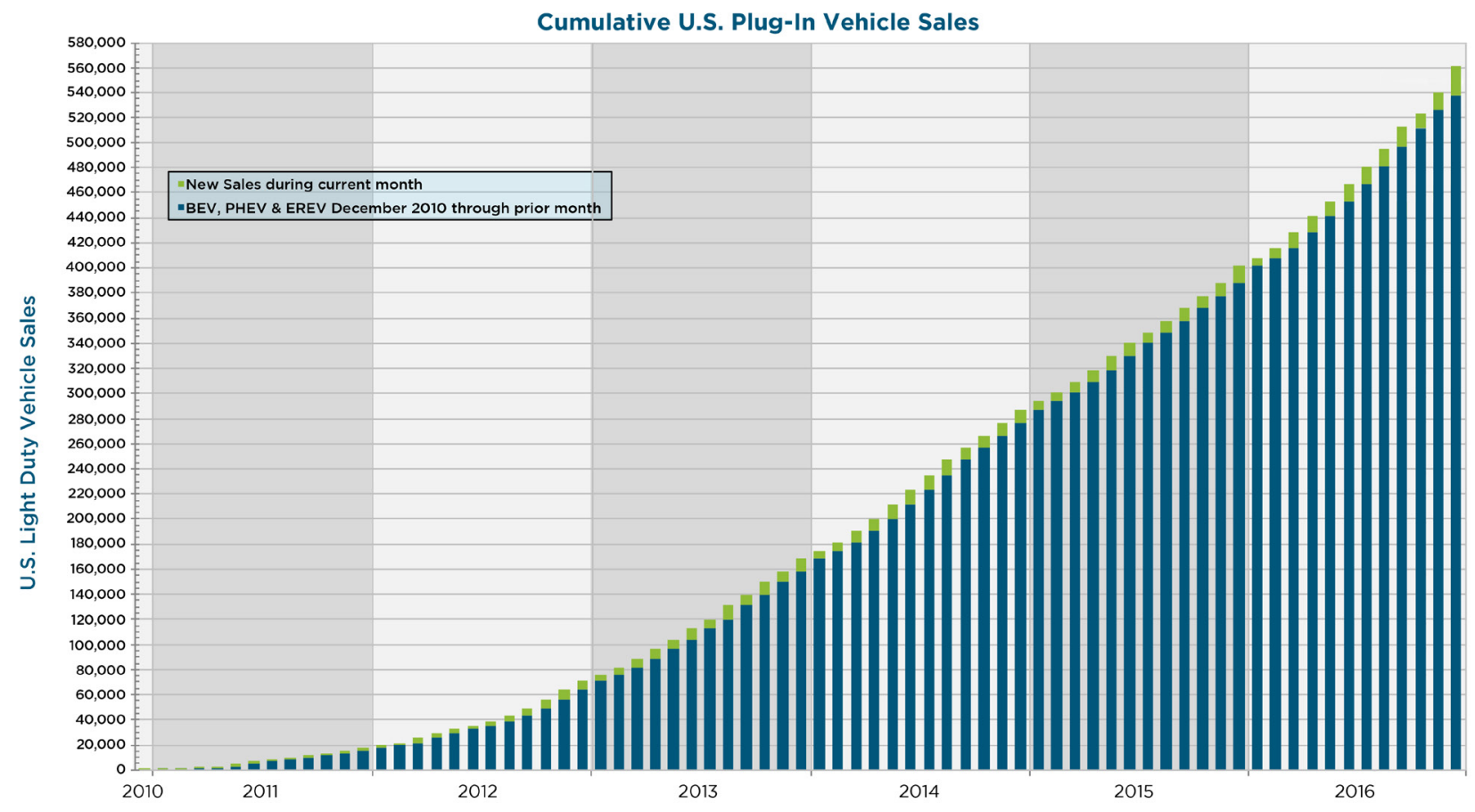

U.S. Plug-in Vehicle Sales. Source: Argonne National Laboratory, Light Duty Electric Drive Vehicles Monthly Sales Updates.

\footnotetext{
9 Yan (Joann) Zhou, "Light Duty Electric Drive Vehicles Monthly Sales Updates," [Online]. [Accessed on 16 February 2017].

Available: http://www.anl.gov/energy-systems/project/light-duty-electric-drive-vehicles-monthly-sales-updates

10 Ibid.

11 “Tesla Model 3 Pre-Orders Whittled Down to 373,000," Autoblog, 19 May 2016. [Online]. [Accessed on 22 February 2017].

Available: http://www.autoblog.com/2016/05/19/tesla-model-3-pre-orders-lower-report/

12 "Liebreich and mcCrone: Electric vehicles - It's not just about the car," Autoblog, 22 August 2016. [Online]. [Accessed on 22 February 2017]. Available: https://about.bnef.com/blog/liebreich-mecrone-electric-vehicles-not-just-car/
} 
through Missouri, Alabama and Georgia, and across the Northeast, have implemented transportation electrification programs that install PEV infrastructure and provide education and outreach efforts.

Charging PEVs is possible at private homes as well as at roughly 15,000 charging stations (including private, federal, state, local, and utility owned stations) across the country. ${ }^{13}$ Through a network of direct current fast-chargers, Tesla has made possible east-west cross-country travel, and northsouth travel along both the east and west coasts. Further, BMW and Nissan are partnering to build an additional 120 fast-chargers in 19 states to facilitate cross-country travel of their PEV models. ${ }^{14}$ However, car manufacturers and charging station suppliers await the release of the communication standard to create additional opportunities between

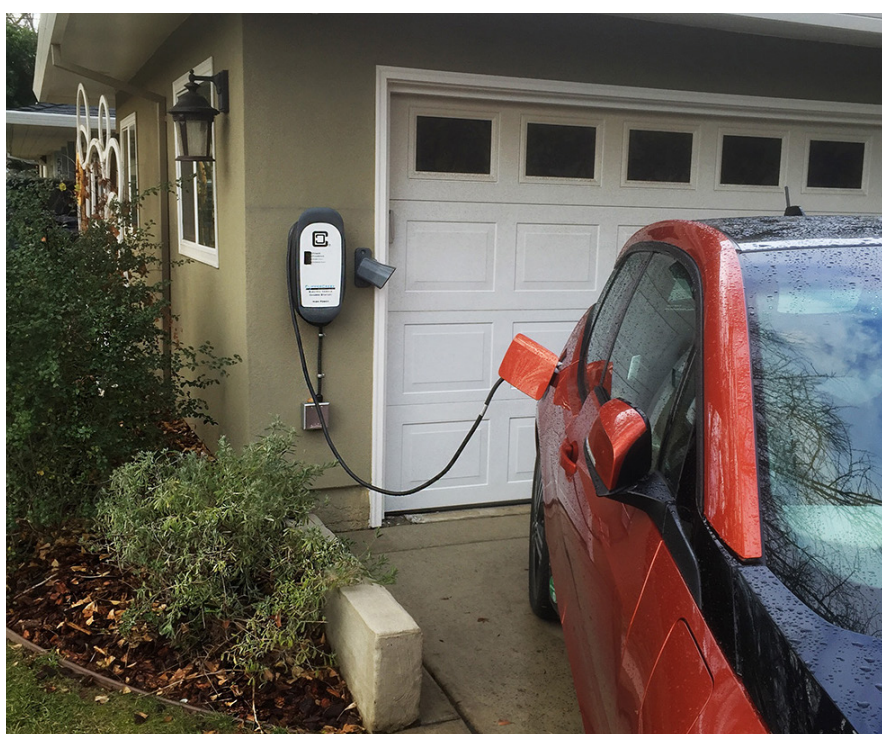

EVSE installation. Source: Clipper Creek the vehicle and the electric grid by offering automated managed charging, reverse power flow, and vehicleto-load capabilities. These measures provide a solid foundation for a transportation future with a sizeable fleet of PEVs pulling energy from the electric grid.

Transportation electrification and its related infrastructure is an emerging market force that encompasses a broad section of the American economy, from the nation's ports and airports to freight and passenger movement and personal transportation. This market relies on the grid for energy and is beginning to incorporate the latest communication technologies to maximize the customer's experience.

\section{"Feeder Models with PNNL found "average" circuits could support high penetrations} of electric vehicles" - Ben Farrow, PSE, August 7,

2014 presenting distribution system impacts from large PEV penetration.

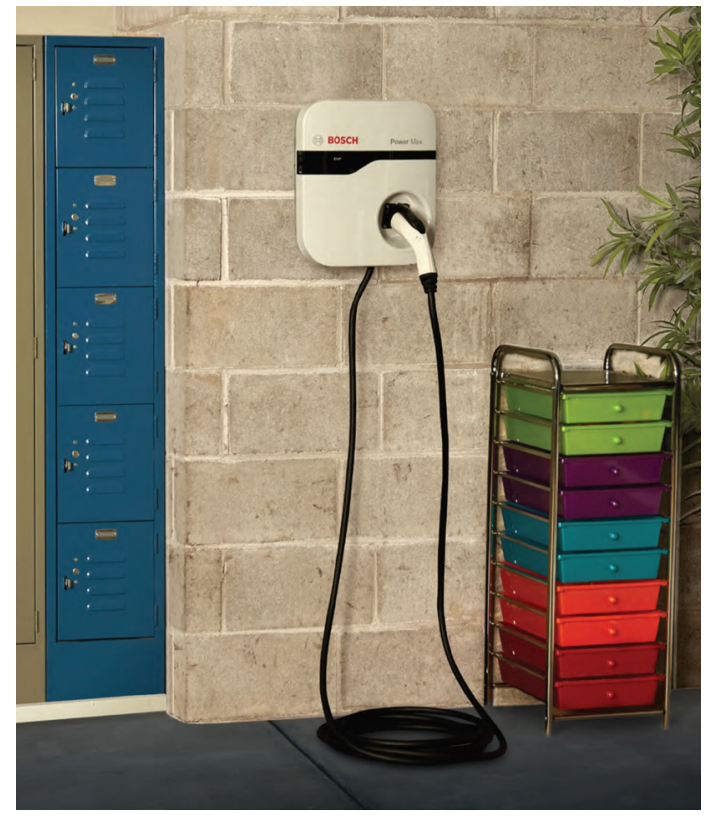

EVSE installation. Source: Bosch

The growth of PEVs is coming at the same time the electricity sector is experiencing significant changes in generation mix and load driven by a variety of factors including new technologies, environmental policy, and consumer expectations. The new technologies are making it possible to operate the electric grid more efficiently

\footnotetext{
13 “Electric Vehicle Charging Stations Locations," Alternative Fuels Data Center [Online]. [Accessed on 14 December 2016]. Available: http://www.afdc.energy.gov/fuels/ electricity locations.html

14 "Nissan and BMW partner to deploy dual fast chargers across the U.S. to benefit electric vehicle drivers," Nissan. 21 December 2015. [Online]. [Accessed on 12 August 2016]. Available: http://nissannews.com/en-US/nissan/usa/releases/nissan-and-bmw-partner-to-deploy-dual-fast-chargers-across-the-u-s-to-benefit-electric-vehicle-drivers?query= Nissan+and+BMW+partner+to +deploy+dual+fast+chargers+across +the+U.S.+to+benefit +electric + vehicle + drivers
} 
and effectively, but it requires capital investments and an increased need for data management and coordination at all levels and among a number of energy system participants. The technology and data revolution also creates a new intersection between transportation, buildings, and electric companies. PEVs present opportunities for growth and innovation, economic gains, improved environmental performance, and new choices for customers looking to reduce their total energy consumption and spending.

The GO15 is a forum for Chief Executive Officers of the largest power grid operators (PGOs) to discuss the challenges of the electric industry. It is comprised of 17 PGOs from six continents that collectively serve over 3.4 billion customers. Three U.S. PGOs are members: CAISO, MISO and PJM Interconnection. In their 2015 Annual Review, GO15 recognized that the future will entail managing increasingly complex electric grids to accomodate increasing renewable energy, electric vehicles, and greater consumer demand flexibility. ${ }^{15}$ To improve or just maintain the reliability and resilience of these future electric grids, the GO15 affirms, "it will be necessary to develop smarter grids by leveraging advanced communication and information technologies that will play an increasingly critical role." Today's electric grid lacks the necessary attributes to meet the power demands of the $21^{\text {st }}$ century. ${ }^{16}$ To address the deficiencies a DOE-wide collaboration, known as the Grid Modernization Initiative (GMI), was launched to set the United States on a cost-effective path to a modern grid.

The electric power industry is increasingly interested in balancing the variability of solar and wind energy with managed vehicle charging, energy storage, and other building technologies - and with good reason. Energy storage can smooth the rapid shifts in renewable output that can lead to fluctuations in customer service voltage. It can also help reduce load during high-demand periods (a service called peak shaving) and provide firming - the guarantee of balancing generation and load at a certain time. Ensuring the reliability of the distribution system as the number of PEVs and its charging infrastructure grow is critical to maintaining both a reliable and economic grid system. ${ }^{17}$

The grid's $21^{\text {st }}$ century evolution is being driven by the widespread use and networking of monitoring systems, distribution automation, advanced inverters, advanced meters, and other intelligent devices. Electric companies increasingly depend on data communications and automated control among millions of devices for reliable grid operations, leaving the electric system exposed to potential cyber security attacks.

\section{Modern Grid and Electric Transportation Uniting Factors}

The following factors unite the modern grid and transportation together to achieve the following:

- A flexible, reliable, efficient, and resilient energy delivery system.

- Data and data management infrastructure that enable the secure management of information.

- A distributed energy architecture that supports integration of renewable resources, energy storage and integrates two-way power flows on the legacy grid system.18

In EPRI's Smart Grid Demonstration Initiative, which involved 47 demonstration projects with 17 utilities, cyber security challenges emerged as one of the initiative's major findings. Several participants witnessed that achieving comprehensive cyber security protection for their operations and IT systems was no easy task. Among the challenges is multiple systems and operators independently gathering and analyzing security information available in different applications and from different vendors. The participants concluded, "Utilities need a coordinated

\footnotetext{
15 “Annual Review 2015,” GO15. Reliable and Sustainable Grids. [Online]. [Accessed 16 August 2016]. Available: http://www.go15.org/wp-content/uploads/2015/07/GO15-Annual-Review-2015-V1_compressed.pdf

16 “Grid Modernization Initiative,” [Online]. [Accessed 20 September 2016]. Available: http://energy.gov/under-secretary-science-and-energy/grid-modernization-initiative

17 Rick Pratt, "PEV/Grid Integration Study," [Online]. [Accessed 11 August 2016]. Available: https://energy.gov/sites/prod/files/2015/07/f24/vss142 pratt_2015 p.pdf

18 Jeffrey D. Taft, “Grid Architecture and the Interactions of Power Systems, Markets, and Grid Control Systems,” [Online]. [Accessed 11 August 2016]. Available: http://gridarchitecture.pnnl.gov/library.aspx
} 
cyber security approach that will enable them to support new applications and legacy systems and to comply with regulations and standards." 19

The relationship between grid modernization and electric transportation is complimentary thus both sectors ought to address critical issues such as reliability, privacy, data management, affordability, and security jointly. As the future evolves, we can benefit from increasingly efficient movement of goods and people in a coordinated, reliable, and environmentally friendly manner.

\section{Opportunities}

The Multi-Lab EV Smart Grid Integration Requirements Study ${ }^{20}$ developed in support of the DOE's Vehicle Technologies Office and Grid Modernization Initiative confirms that effective and efficient integration of PEVs with the grid allows electric companies to "reduce peak power requirements, regulate grid voltage and frequency, and balance the intermittent power output of distributed energy resources (DERs)."21 The metering and communications infrastructure necessary for PEVs to provide grid services should be well defined, standardized, and developed with sophisticated cyber security controls.

There are numerous opportunities resulting from a modern grid well-integrated with electric transportation that could positively impact both sectors. The bulleted list below describes several of them where the significance of the opportunity will vary based on the specifics of the existing grid and the local PEV market growth. The value of each opportunity will benefit from careful evaluation and management as the vehicle population grows in the future.

- Supporting Grid Modernization: A modern grid promotes long-term system reliability, efficiency, resiliency, and consistent levelized cost, all of which increase confidence in a robust energy source and boost the value of electricity as a transportation fuel. Increased electrical load from transportation may help offset the costs of grid modernization when integrated into overall grid planning.

- Energy Usage Data Management: The current trend to provide integrated wireless national PEV charging networks transcends utility boundaries. These networks maintain large data sets about electrified transportation in a specific location. These data, when shared with electric companies, can enable increased grid efficiency, more accurate load prediction, enhanced value of transportation electrification, and improved consumer satisfaction.

- Smart Cities: Smart cities are developed urban areas that create sustainable economic development and high quality of life by excelling in economy, mobility, environment, people, living, and government.22 Across the world, communities are working to become smart cities. Electricity, visibility into vehicle movements, data management, and data analytics are key components of a smart city's success. Electric companies can be key partners in PEV integration with the grid with the possible result of the additional load and data visibility offsetting some of the investment costs of grid modernization.

\footnotetext{
19 Michael Matz, “Smarter on Smart Grids," EPRI Journal, 24 July 2015. [Online]. [Accessed 23 August 2016].

Available: http://eprijournal.com/epris-7-year-smart-grid-demonstration-initiative-top-8-takeaways/

20 “Multi-Lab EV Smart Grid Integration Requirements Study," National Renewable Energy Laboratory (NREL), NREL/TP-5400- 63963, May 2015. [Online]. [Accessed 27 August 2015]. Available: http://www.nrel.gov/docs/fy15osti/63963.pdf

21 “Emissions from Hybrid and Plug-In Electric Vehicles," Alternative Fuels Data Center [Online]. [Accessed 7 July 2016]. Available: http://www.afdc.energy.gov/vehicles/electric_emissions.php

22 BusinessDictionary.com, "smart city," [Online]. [Accessed 7 July 2016]. Available: http://www.businessdictionary.com/definition/smart-city.html
} 
- PEV Flexible Charging: Projected increase in electricity demand from uncontrolled PEV charging is minimal. ${ }^{23}$ If controlled, PEV charging can provide the electric power grid the flexibility necessary for active load management, as well as to address a variety of challenges, including the integration of renewable energy.
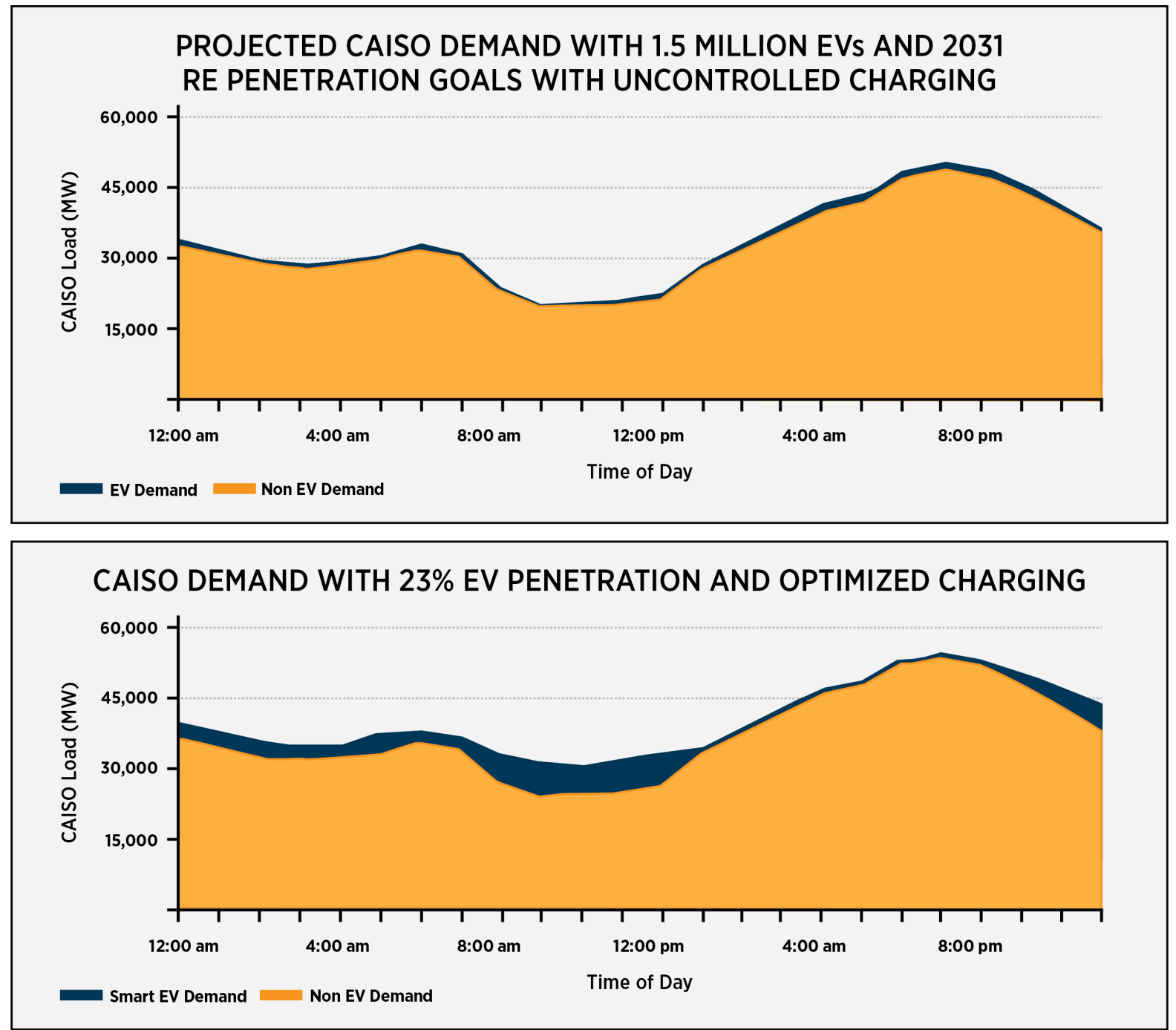

CAISO Demand including PEVs. Source: Rocky Mountain Institute

- Big Data: Through their onboard communication systems such as General Motors' OnStar, PEVs are already part of a massive data system. Electric companies are also collecting and managing customer data to determine voltage needs, distribution system analysis, and customer billing. Allowing these two systems to share key information can improve PEVs, the grid, and the customer experience. A potential business opportunity exists for electric companies and others to manage this "big data." Electric companies have a regulatory requirement to manage customer and system control data in an efficient, private and secure manner, potentially making them well-suited to manage PEV charging data as well.

23 Chris Nelder, James Newcomb, and Garrett Fitzgerald, "Electric Vehicles as Distributed Energy Resources," Rocky Mountain Institute, 2016 [Online]. [Accessed 16 February 2017]. Available: http://rmi.org/pdf evs_as_DERs 
- HAN System Interconnection: As one of the largest energy users in the home, the PEV when connected to the HAN system can be an integral component of any energy management system.

- Autonomous Plug-In Cars Deployment: Recent studies indicate $90 \%$ to $95 \%$ of traffic accidents are due to driver error and that transitioning to automated vehicles could significantly reduce injuries and deaths from traffic accidents. ${ }^{24,25}$ In the 2009 National Household Travel Survey conducted by the U.S. Department of Transportation, the average person trip length is 9.7 miles, down slightly from 10.0 miles in 2001,26 well within the range of PEVs, making these vehicles suitable for automated driving. Not only could autonomous plug-in cars make transport safer, but they could provide improved and increased mobility in a way that does not increase greenhouse gas emissions. Autonomous plug-in cars could also offer independent mobility for low-income people 27 and over 20 million Americans that cannot qualify for a driver's license. This independent mobility could increase access to healthcare for those unable to drive and without access to public transit. Deployment of autonomous plug-in cars could result in a different charging infrastructure than in the case of non-autonomous PEV fleets with sales volume playing a key role in infrastructure as well. When these vehicles come off the road for charging they will need access to a reliable source of energy, in particular for communications. This reliability may, by definition, be at a higher level than currently planned for communication towers connected to the grid, supporting the justification of new technology, new control systems, and larger backup power.

- Economic and Health Benefits: Grid modernization is closely aligned with the grid's ability to become cleaner. Clean power generation reduces criteria pollutants and greenhouse gas emissions leading to significant environmental and health benefits. In an Argonne report released in June 2016, researchers calculated that electrifying light-duty vehicles would reduce the grams of carbon dioxide equivalent per mile by $26 \%$ per vehicle assuming current technology and as much as $91 \%$ if renewable energy is assumed as the electricity source. ${ }^{28}$ Alignment of local, state, and federal energy regulators is essential to realize this potential.

- Third Parties: The key to the modern grid is enhanced data collection and management systems that continue to enable the system to adjust real-time to fluctuations in supply and demand. PEVs are a critical component of this data structure. In many areas, third parties can operate between electric companies and consumers and use system data to provide services for a profit. These players should to comply with the same cyber security, data or privacy standards.

- Vehicle-to-Home Emergency Energy Provision: The PEV can serve to provide back-up power to the home in a weather emergency that has caused a loss of power, especially to power smaller digital loads in today's modern homes.

- Energy Storage to Grid: PEV advanced battery systems could become stabilizing components of the distribution system. Two-way flow of energy, enabling the stored battery energy to be used by the grid operator when necessary, has the potential to help reduce system costs during peak periods, balance the variability of renewables, and provide ancillary services.

\footnotetext{
24 "Report reveals autonomous vehicles can reduce traffic accidents by 95\% in UK," roadtraffic-technology.com [Online]. [Accessed 22 August 2016 ]. Available: http://www.roadtraffic-technology.com/news/newsreport-reveals-autonomous-vehicles-can-reduce-traffic-accidents-by-95-in-uk-4812182/

25 “Self-driving cars could save more than 21,700 lives, \$450B a year," Computerworld [Online]. [Accessed 22 August 2016]. Available: http://www.computerworld.com/article/2486635/emerging-technology/self-driving-cars-could-save-more-than-21-700-lives-450b-a-year.html

26 “Summary of Travel Trends: 2009 National Household Travel Survey," U.S Department of Transportation Federal Highway Administration, FHWA-PL-11-022, June 2011. [Online]. [Accessed 24 August 2016]. Available: http://nhts.ornl.gov/2009/pub/stt.pdf

27 Todd Litman, “Autonomous Vehicle Implementation Predictions, Implications for Transport Planning,” Victoria Transport Policy Institute, December 10, 2015. [Online]. [Accessed 22 August 2016]. Available: http://www.vtpi.org/avip.pdf

28 Table 52. GHG emissions for the FUTURE TECHNOLOGY reductions shown in Figure 19 (g CO2e/mile). "Cradle-to-Grave Lifecycle Analysis of U.S. Light-Duty VehicleFuel Pathways: A Greenhouse Gas Emissions and Economic Assessment of Current (2015) and Future (2025-2030) Technologies," Argonne National Laboratory (ARL). ANL/ESD-16/7 Rev. 1, 01 June 2016. [Online]. [Accessed 18 January 2017]. Available: https://greet.es.anl.gov/publication-c2g-2016-report
} 


\section{Conclusions}

PEVs are gaining market share making electric transportation a very real and promising load for the electric power sector. These loads offer lots of potential for electric companies to address variability and regulation within the system with targeted capital investments. To realize the full potential of the opportunity, however, several of the technical challenges should be tackled. With some thoughtful planning and analysis, transportation electrification and grid modernization efforts can provide opportunities for growth and innovation in both industries. A modern grid that is well equipped to handle the additional electric transportation load and reap the benefits from the intersection of the transportation and electric power industries, could enrich the customer experience for vehicle owners, and contribute to an enhanced grid with real environmental benefits for all customers.

\section{Other Resources}

There are several resources that can provide further information. In addition to the resources referenced in this paper, take advantage of the following papers, reports, and presentations to learn more about the intersect between grid modernization and electric vehicle transportation.

\section{DOE Cooperative Agreement DE-} OE0000194: The CCET Smart Grid Regional Demonstration Project (SGRDP) entitled, "Technology Solutions for Wind Integration in Electric Reliability Council of Texas," commonly known as Discovery Across Texas is partially funded by the DOE cooperative agreement DE-OE0000194. The project looked at consumers' response to pricing signals and using fleet vehicles for Fast Responding Regulation Service. An interim report for this project is at https://www.smartgrid. gov/files/CCET_Initial_TPR_Rev0_Chg1_2013 12-30 Final.pdf and a presentation by ERCOT on the results of the fleet vehicle demonstration is at http://www.ercot. com/content/wcm/key documents_lists/53418/5. FRRS Frito_Lay 02192015 revised_pdf.

\section{Electric Vehicles as Distributed Energy \\ Resources: Find out more about Rocky Mountain Institute's finding based on numerous pilot projects (http://www.rmi.org/Content/Files/ RMI_Electric_Vehicles_as_DERs_Final_V2.pdf).}

EV Project: The EV Project is the largest deployment and evaluation project of electric drive vehicles and charging infrastructure to date. The data collection phase of The EV Project captured almost 125 million miles of driving and 4 million charging events. The findings are in several reports, maps, white papers, infrastructure plans, and presentations on The EV Project website at https://avt.inl.gov/project-type/ev-project.

Grid Modernization Initiative: Visit the GMI website at http://energy.gov/under-secretary-scienceand-energy/grid-modernization-initiative to find out more about the initiative, its projects, and partnerships.

Smart Grid Investment Grant Program: Under the U.S. Department of Energy's (DOE) Smart Grid Investment Grant (SGIG) program, six utilities evaluated operations and customer charging behaviors for in-home and public electric vehicle charging stations. (https://www.energy.gov/oe/articles/now-availableevauating-electric-vehicle-charging-impacts-andcustomer-charging). 


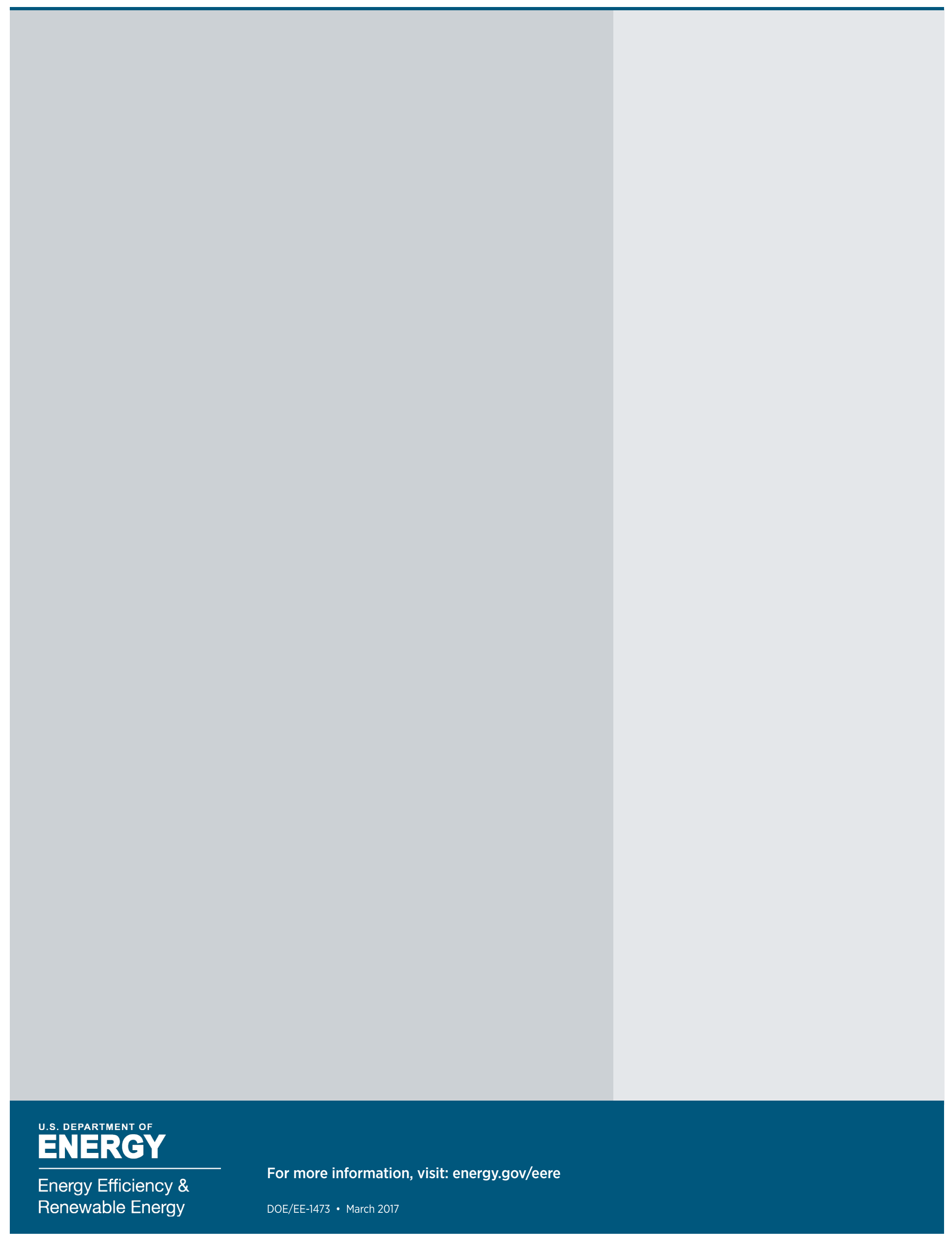

